TRADUÇÃO 



\title{
TEXTO E PERFORMANCE NA ÁFRICA
}

\author{
Karin Barber iD
}

Universidade de Birmingham

Tradução de

Yves Marcel Seraphim iD $\triangle$

PPGAS/DAN/UnB

Publicado originalmente em Oral Tradition (2005). Agradeço imensamente à Karin

Barber pelo modo empolgado com que recebeu minha proposta de tradução e por sua paciência nesse processo. Além disso, sou grato a ela e a Paulo Fernando de Moraes Farias por reverem certos aspectos da tradução. 


\section{ABSTRACT}

If written texts usually involve some kind of performative dimension, oral performances also entail the constitution of a text. American linguistic anthropology uses the term 'entextualization' for the process by which stretches of spoken discourse are detached from their immediate context and rendered repeatable and thus transmissible. In African oral poetry there are entextualizing strategies which involve rendering discourse object-like: by making it the focus of exegesis, or by presenting it as quotable, thus foregrounding the perception that these words pre-existed their present moment of utterance and could continue to exist after it. However, African oral praise poetry is also highly dynamic. Text is not consolidated in order to constitute it as an unchanging monument, but rather so that it can be re-activated in a new context of utterance, where it has an effectual engagement and dialogic force. Thus the performative and the entextualizing dimension can be seen to be inseparable and mutually dependent.

\section{RESUMO}

Se os textos escritos geralmente envolvem algum tipo de dimensão performativa, as performances orais também implicam a constituição de um texto. A Antropologia Linguística americana usa o termo “entextualização" para o processo pelo qual trechos de discurso falado são destacados de seu contexto imediato e tornados repetíveis e, assim, transmissíveis. Na poesia oral africana existem estratégias de entextualização que envolvem fazer do discurso algo objetivável: ao torná-lo foco de exegese ou ao apresentá-lo como citável, ressaltando assim a percepção de que essas palavras preexistiam ao seu momento presente de enunciação e depois deste poderiam continuar a existir. No entanto, os cânticos de louvor africanos são também altamente dinâmicos. O texto não é consolidado de modo a constituilo como monumento imutável. Em vez disso, a consolidação ocorre para que ele possa ser reativado em um novo contexto de enunciação, no qual tenha engajamento efetivo e força dialógica. Logo, pode-se observar que a dimensão performativa e a dimensão entextualizante são inseparáveis e mutuamente dependentes.

\section{TEXTO E PERFORMANCE}

Nas tradições literárias escritas, a distinção entre texto e performance parece óbvia. O texto, manuscrito ou impresso, é um artefato permanente enquanto a performance é a realização ou a concretização única, irrepetível do texto, uma realização que "confere vida ao texto", mas que, ela mesma, está condenada a morrer ao fim das vibrações vocais que a enunciam. O texto fixa, a performance aviva. Mas, mesmo em tradições escritas, há todo tipo de relações diferentes possíveis entre um "texto" e sua "performance". Textos escritos podem ser roteiros, deixas ou estimulantes para a performance oral, e podem também ser registros, resultados ou subprodutos dela. Mesmo textos em geral considerados como puramente pertencentes à esfera escrita podem ter uma dimensão performativa. Se, como é verdade em muitas tradições, o texto depende da performance, e a performance do texto, estudos de literatura comparativa deveriam nos ajudar a conceituar a natureza e os graus dessas variantes relações de dependência.

O campo de possibilidades é vasto. Em uma das pontas do leque de possibilidades estão casos como o da commedia dell'arte italiana do século 
XVI, em que o roteiro não seria mais que uma folha de papel, listando a sequência dos episódios do enredo e os personagens que neles aparecem. Os atores pegavam essas folhas de papel literalmente no momento de entrar no palco, escrutinizavamnas e imediatamente começavam a improvisar (Duchartre 1966: 30). Aí o texto é essencial, pois ele é o esboço da estrutura da obra, sem o qual os atores não teriam condições de atuar. Mas o material da performance é fornecido pelo repertório de convenções, trechos pré-preparados, gestos, ditos espirituosos, e piadas, de que dispõem os atores, e que formam a tradição verbal e gestual destes. Embora esse repertório fosse oral e incorporado, ele também agregava concetti, fórmulas verbais pré-preparadas, coletadas pelos atores em seus cadernos de anotação e engenhosamente arquitetadas para serem adaptáveis a diversas situações. O objetivo era conhecer a fundo e utilizar eficazmente a retórica do palco tão bem que as passagens improvisadas fossem indistinguíveis em tom das passagens escritas pré-preparadas (Lea 1962: 105). Aí o texto escrito dá alento e arrimo a uma tradição cuja meta e produto final é uma performance ao vivo. $\mathrm{Na}$ outra ponta do leque de possibilidades estão formas como o romance realista do século XIX, em que um discurso escrito generosamente específico e detalhado cria um mundo textual completo, crível e autônomo pelo qual o leitor é absorvido. Mas o interesse narrativo desse tipo de romance está fundado, como observa Garrett Steward, na tensão entre o mundo ficcional criado e a solicitação contínua do texto para que o leitor desempenhe uma função no evento de leitura, "recrutando-o" através de uma gama de dispositivos retóricos, de modo que figure como participante na constituição da narrativa: "você, leitor, é, portanto, parte do roteiro (Stewart 1996: 6). O texto escrito não apenas oferece ao leitor implícito uma série de posições em relação ao próprio texto, ele também sugere como o ato de leitura deve desenrolar-se e estimula o leitor real a manter uma consciência de sua performance como um leitor, mesmo nas narrativas mais absorventes. Aqui o texto especifica muito mais do que o roteiro da commedia dell'arte: além de criar um mundo, ele também instrui o leitor em como participar da realização desse mundo na imaginação.

A teoria crítica tem proposto modelos amplamente diferentes de como os textos literários especificam sua própria "performance" nos atos da leitura. Para o filósofo Collingwood, uma leitura verdadeira (seja ela de um texto literário ou de uma pintura) era totalmente especificada pelo texto, pois resulta do ato de recriação da obra de arte pelo leitor, retraçando os mesmos passos pelos quais o artista originalmente constituiu o texto ou a imagem. Era, portanto, a performance 
do ato de criação artística, roteirizada por cada detalhe da obra de arte em si (Collingwood 1938). A crítica pós-estruturalista diria quase o oposto: um texto é capaz de retribuir sua leitura quando ele se abre a muitas possibilidades de significação e incita o leitor ou leitora a praticar seus próprios atos de criação, estimulados, mas não coagidos pelo texto - criação que frequentemente emerge na tangente ou em oposição ao projeto aparente do próprio texto (Barthes 1974).

Teóricos literários, então, estão prontos para abraçar a ideia de que os textos escritos provocam, acarretam ou coexistem com algum tipo de dimensão performativa. No entanto, eles estão menos aptos a considerar a reivindicação correspondente de que as performances dentro de tradições orais implicam algum tipo de dimensão textual.

Nas tradições orais, a copresença da performance e do texto é, com certeza, mais difícil de se enxergar, uma vez que não há algum documento visível e tangível para contrastar com os enunciados fugazes. Não obstante, é evidente que o que acontece na maioria das performances orais não é puro desaparecimento, instantaneidade, fugacidade e emergência no instante em que os enunciados evanescem. Em geral, trata-se justamente do contrário. Há uma performance mas ela é uma performance de algo. Entende-se que algo identificável preexistiu o momento de enunciação. Ou, de outro modo, entende-se que algo é constituído no enunciado, algo que pode ser abstraído ou apartado do contexto imediato e reincorporado em uma performance futura. Mesmo que o único lugar em que esse "algo" possa ser considerado existente seja na mente e nas memórias das pessoas, ainda assim ele é distinguível do enunciado real que é imediato e que imediatamente desaparece. Esse "algo" pode ser referenciado. As pessoas podem falar da "história de Sunjata” ou dos “louvores a Dingaan”, em vez de falar da performance em uma ocasião particular de um narrador ou cantador de louvor em particular. E essa capacidade de serem abstraídas, de transcenderem o instante, e de serem identificadas independentemente das instâncias particulares é a razão de ser das tradições orais. Elas são "tradições" porque é sabido que são compartilhadas e herdadas; elas podem ser compartilhadas e herdadas porque foram justamente constituídas para que sejam destacáveis do contexto imediato e capazes de serem transmitidas no tempo e disseminadas no espaço. Os criadores e transmissores dos gêneros orais usam todos os recursos à sua disposição para converter enunciados em textos quase autônomos.

Se há desassossego com a ideia de gêneros orais como textos, isso é um legado de uma batalha longa e, por fim, bem-sucedida que foi travada pela teoria 
da performance e do folclore dos anos sessenta em diante contra uma empobrecedora abordagem escritocêntrica à oralidade. A descoberta estimulante da importância da "composição em performance", da improvisação, da interação com a plateia, do gesto, do tempo, do ritmo e da expressão corporal, do emergente e do processual significavam que a teoria da performance, ao menos em seus primeiros estágios, era fortemente oposta a qualquer coisa que se assemelhasse ao conceito de "texto" na crítica literária. Houve tempos em que quase aconteceu uma caça às bruxas contra o conceito de texto, o qual, juntamente com "estrutura", "objeto", "fixidez" e "sistema", foram acusados de distorcer e reificar a natureza fluída, emergente, improvisatória, dialógica e corporal da performance. Texto e performance eram vistos não apenas como radicalmente distintos, senão como inimigos um do outro. Mas já que a batalha por uma abordagem performativa foi mais ou menos ganha, torna-se possível agora reunir esses conceitos separados artificialmente. De um lado, uma definição mais flexível e inclusiva de "texto" foi proposta, não confinada ao discurso escrito ou mesmo ao verbal. W.F. Hanks (1989: 95) propõe como uma definição operante "qualquer configuração de signos que seja coerentemente interpretável por alguma comunidade de usuários" - englobando não apenas discursos orais e escritos de inumeráveis tipos, mas também pintura, música e filme. Por outro lado, antropólogos trabalhando com tradições orais começaram a tentar explicar como a performance momentânea e fugaz pode, ainda assim, ser encarada como algo abstraído e apartado do fluxo do discurso cotidiano. Começamos a enxergar como se investe trabalho na constituição de gêneros orais de modo a serem capazes de repetição, avaliação e exegese - isto é, capazes de serem tratados como objeto de comentários - pelas comunidades que os produzem, e não somente pelo coletor ou pelo etnógrafo.

A possibilidade de pensar sobre o texto nesses termos tem crescido bastante recentemente através da noção de "entextualização" desenvolvida por antropólogos linguistas dos EUA (ver em especial Silverstein \& Urban 1996). Entextualização é o "processo de tornar uma instância dada de discurso como texto, destacável de seu contexto local" (Silverstein \& Urban 1996: 21). Quanto mais destacável for um trecho de discurso, mais compartilhável e transmissível ele se torna (Urban 1991). Os mecanismos de entextualização identificados por Silverstein e Urban são opções linguísticas que delimitam a dêixis e outras formas de dependência do contexto imediato. Assim, o discurso que é conduzido na terceira pessoa é mais destacável do que os discursos na primeira e na segunda pessoa, os quais tendem a evocar uma 
resposta do ouvinte, sugando o discurso para o aqui e agora. São conduzíveis à destacabilidade antes as frases declarativas do que as interrogativas, antes o passado distante do que o presente. Mitos, situados no passado remoto e com terceiras pessoas em um lugar longe dos falantes e dos ouvintes do presente, são o exemplo por excelência do discurso entextualizado, e o discurso que é produzido coletivamente é mais independente do contexto imediato do que enunciados individuais: portanto, algumas tradições de narração de mitos requerem a participação de um auxiliar que em dados momentos pergunta "e o que mais?", ou que atua como "ponto" recordando a narrativa ao narrador para sublinhar o fato de que a narrativa é compartilhada pela comunidade que tem a responsabilidade coletiva de produzi-la (Urban 1996: 39-40).

Talvez porque os principais exemplos etnográficos no livro de Silverstein e Urban sejam de culturas ameaçadas ou desaparecendo nas Américas do Norte, Central e do Sul, grande parte da discussão da entextualização gira em torno dos processos de elicitação, gravação e transcrição de narrativas a partir de poucos indivíduos. No livro, há uma indecisão entre tratar a entextualização como um processo de construção cultural que ocorre em todas as culturas, incluindo as completamente orais, e tratá-la de forma mais restringida, como o processo de tornar discursos orais em "textos" ao escrevê-los. Esta última perspectiva levanta questões importantes sobre como "textos" em potencial são identificados e definidos, e sobre como a interação colaborativa do falante nativo e do etnógrafo molda o produto final. No entanto, para os propósitos do presente argumento, é mais produtiva a primeira - mais inclusiva - noção de entextualização.

Um olhar aos gêneros orais africanos revela um repertório amplo de estratégias de entextualização, nem todas envolvendo a terceira pessoa ou o passado remoto. Na verdade, um dos gêneros africanos mais difundidos, de importância central na vida social e política, o cântico de louvor [praise poetry $]^{1}$, não poderia ser mais diferente dos mitos ameríndios usados como modelo de discurso entextualizado. O cântico de louvor é notável por seu direcionamento vocativo na segunda pessoa, e por sua evocação simultânea do passado e do presente trazendo ao centro da comunidade viva os poderes e os potenciais dos predecessores mortos. O texto é consolidado e tornado destacável

<?> [N.T.] Para a tradução da expressão inglesa praise poetry, a qual coteja ao longo do artigo a tradição oral Yorùbá dos oríkis, adotou-se a tradução "cântico de louvor", acordando com o emprego que a literata e professora da UFMG, Leda Martins, realiza quando menciona os oríkis. 
de seu contexto imediato - mas apenas de tal modo que possa ser reativado e reencaminhado em um novo contexto de enunciação, em que tenha força dialógica e um engajamento eficaz. As diversas estratégias de entextualização nos gêneros do cântico de louvor africano poderiam ser enumerados e ilustrados por extenso, antes, porém, o que proponho fazer aqui é tentar identificar seu modo comum e subjacente de operação. Isso é fazer do discurso algo objetivável [object-like]: ao torná-lo o foco de comentário e de atenção exegética ou ao apresentar texto como citável, dessa maneira, enfatizando a percepção de que essas palavras preexistem a seu momento presente de enunciação e podem ainda continuar a existir posteriormente.

Ao esboçar tal modalidade, quero enfatizar que ao se constituir o texto enquanto objetivável, esses gêneros africanos não renunciam à fluidez e à qualidade improvisatória que a teoria da performance explorou com tanto sucesso. Em vez disso, trata-se da própria consolidação de pedaços examináveis, citáveis, repetíveis de textos que fazem possíveis os processos dinâmicos da incorporação fluída, da reinflexão, e da reciclagem, os quais são os marcos da performance do cântico de louvor ao longo do continente. Assim, em vez de procurar substituir um modelo processual dos gêneros orais por um de fixidez semelhante à escrita, o que pretendo mostrar é que constituir o texto como algo objetivável é a condição de possibilidade de uma poética fluida. Meu segundo argumento, que necessitará elaboração em um trabalho futuro, é que as técnicas de entextualização aqui discutidas envolvem uma certa reflexividade - uma consciência do texto enquanto algo criado a fim de ser exposto, recontextualizado e refletido. Atentar a tais técnicas poderia, então, potencialmente providenciar pistas aos modos de autoentendimento e autointerpretação dos coletivos que as criam.

\section{TEXTOS ANEXADOS A OBJETOS}

A indicação mais vívida do desejo de consolidação da fala efêmera é a prática difundida de anexar formulações verbais a objetos materiais. $\mathrm{O}$ vasto número de textos-objetos variados e engenhosos que florescem na África subsaariana atesta o impulso de gerar formulações verbais que ultrapassem espaço e tempo por meio de um objeto correspondente. A tábua lukasa dos Luba, as mensagens em miçangas dos Zulu, os récades ou cetros de mensagem em Daomé, os símbolos adinkra dos Asante, pesos de ouro, pontas de guarda-chuva e uma série de outros repositórios materiais e gatilhos dememória operam em diferentes modos para transcender o tempo e fixar ou capturar o texto em uma forma 
material. Yankah descreve um sistema pelo qual, em certas áreas falantes de Akan em Gana, ditados recém-cunhados eram "registrados" ao serem associados com um objeto mnemônico, o qual logo seria pendurado por uma corda no teto da casa de um guardião de provérbios. Por exemplo, uma mulher que se divorciou e se casou novamente três vezes com o mesmo homem cunhou o ditado irônico: "O osso vazio - quando o lambe, seus lábios doem; quando o deixa seus olhos o seguem". O guardião de provérbios registrou esse ditado pendurando um osso de verdade em uma corda. Se visitantes perguntassem a respeito do osso, além de dizer o ditado em si, o guardião de provérbios seria engatilhado a descrever a mulher e as circunstâncias em que ela o cunhou (Yankah 1994). Portanto, o provérbio é triplamente objetificado. Ele surge de um objeto material - o osso (ou a ideia do osso) que inspirou o enunciado metafórico da mulher. Ele é trazido à baila por um objeto material equivalente - o osso na corda do guardião. E é reativado por um discurso contextualizante que toma o próprio provérbio enquanto um objeto - um objeto de atenção, explicação e avaliação.

O objeto - o osso na corda - é mais do que mnemônico. Ele parece se apresentar como um enigma ou desafio: por que o osso está ali? Qual explicação pode se dar para sua presença na corda do guardião? Os objetos suspensos engatilham perguntas dos visitantes, as quais o guardião busca responder da forma mais completa possível. Por sua vez, o provérbio em si anexado ao osso provoca e requer explicação. Tal qual o osso, o provérbio é apresentado como um objeto opaco, cujo significado somente se torna aparente quando é banhado em um mar de detalhes contextuais e históricos, "mar" este que não está codificado no objeto ou no provérbio, mas é transmitido em outro gênero - a narrativa pessoal - que corre em paralelo.

\section{OBSCURIDADE E EXEGESE}

Pode-se enxergar essa associação de textos verbais com objetos verdadeiros não como um pitoresco sistema mnemônico, mas como a forma mais visível de um impulso muito mais amplo para consolidar palavras faladas em formulações compactas exigindo uma expansão ou uma elaboração subsequente por parte do intérprete. A exegese pode ocorrer dentro do texto ou fora dele, em outro gênero. A necessidade de comentários é aumentada quando a formulação é alusiva, opaca, truncada ou obscura de outra maneira.

Um aspecto bastante característico do cântico de louvor na África é a frase substantivada, uma frase convertida em um epíteto. No processo da conversão, a declaração se torna compactada; ela perde seus marcadores temporais e se torna uma 
alusão a um estado atemporal do ser. Assim, o oríki (atribuição ou apelação) Yorùbá Dínà-máyà ("bloqueia-estrada-não-se-move") é uma substantivação derivada da frase "Ó dínà, kò sì yà": "Ele bloqueou a estrada e não se moveu". Uma frase que se refere a um evento no tempo performado por um agente é convertida em um epíteto por meio da remoção dos marcadores de agência pronominal e do aspecto verbal. Logo, os eventos são transformados em qualidades; coisas que ocorreram no tempo se tornam atributos atemporais. A passagem ou o epíteto substantivado flutuam acima de contextos específicos de ação, sugerindo que o dono do epíteto existe em um estado permanente de ser elegível a tal atribuição. Essa forma de entextualização é comparável à constituição do discurso mítico debatido por Silverstein e Urban (1996). Mas ela tem outro efeito entextualizador ainda mais poderoso: enunciados compactos desse tipo omitem muito. As ações e os eventos que lhes deram origem não são recuperáveis por meio das palavras em si. Os enunciados sugerem narrativas, mas não as contam. A arte da exegese, portanto, consiste em expandir essas formulações lacônicas e reinstalar o/a agente a seu contexto de ação.
O oríki "Bloqueia-estrada-não-se-move” é pareado com outro epíteto, $A$-dóminú-kojo:"Aquele que enche o covarde de apreensão”. Esses louvores pertencem a Wínyomí, um grande caçador de Òkukù do século XIX e a seus descendentes ${ }^{3}$. Os louvores evidentemente assinalam algum tipo de feito corajoso, mas apenas quando são expandidos por meio de um gênero separado, o ìtàn - ou narrativa - é que eles adquirem seu significado completo. Wínyomí tinha um amigo de uma cidade vizinha cujo filho, um mascarado, matou um homem durante uma excursão dos mascarados ancestrais. O culpado, ciente da reputação de Wínyomí de ser um lutador formidável e curador, foi até ele em busca de refúgio. Em massa, os parentes da vítima então marcharam para Òkukù a fim de requisitar que Wínyomí entregasse o criminoso. Wínyomí saiu para encontrá-los, ficou no meio da estrada e disse: - "Vou fechar meus olhos e quando eu os abrir, vocês todos terão desaparecido". Tamanho foi o horror que essa ameaça inspirou que a multidão inteira fugiu, fazendo o prenúncio de Wínyomí se tornar verdade. Assim, o curto par de epítetos - Dínà-má-yà, a-dóminú-ko - tem seu próprio contexto narrativo, independente do contexto concreto da performance. Para ter seu significado, 
o par não depende de outras atribuições de dentro da performance, tampouco do contexto em que é enunciado. A "obscuridade" desses epítetos reside no fato de que a expansão narrativa reside fora do texto em si. O ouvinte experiente tem que conhecer a história para dar total sentido ao epíteto. Há uma divisão do trabalho na constituição do significado textual, a qual é ampliada pelo fato de que em Òkukù enquanto oríkì são geralmente performados por mulheres, ìtàn são geralmente contados por anciões. ${ }^{3}$ A exegese é, portanto, construída na constituição do significado. Ela implica tratar o epíteto como um objeto de atenção e explicação. O povo Yorùba está normalmente bastante preparado para oferecer exegeses engenhosas, as quais, por vezes, envolvem análises de cada sílaba de frases tais como Dínà-má-yà.

Em contrapartida, quando os homens anciões contam a história de sua linhagem, seu ìtàn geralmente depende do oríkì para ir de um ponto ao outro. Um narrador pode contar um episódio histórico e então concluir: "E é por causa disso que somos chamados tal-e-tal”. Ou talvez ele introduza um novo episódio ao nomear um personagem da narrativa, citando um de seus ou epítetos de louvor e então explicar seu significado. Ajíbóyè, da linhagem oba em Òkukù, fez ambos os procedimentos em um dos episódios das origens lendárias da cidade e da família real. Ele começou o episódio ao anunciar: - "Um dos oríki [da cidade] é àyàbùèrò". Esse epíteto é uma expressão construída de forma estranha e cujo significado não é aparente de imediato. Tendo apresentado esse enigma, Ajíbóyè prosseguiu explicando (adaptado de Barber 1991: 65):

\begin{abstract}
Isso é assim devido a uma inundação famosa. O rio Òtìn corria perto da cidade. Certo ano choveu e choveu e o rio alagou o quintal de todo mundo, todos galinheiros, cercas de bodes e pombais foram carregados. Mas após cerca de doze dias, quando o alagamento baixou, todos animais ainda estavam vivos. O rio foi reconhecido como um rio beneficente $\mathrm{e}$ foi honrado com o nome à yà bù èrò: a-coisa-pelo-que-se-para-e-se-escava pertencendo aos estrangeiros [i.e. o rio em cujas águas os estrangeiros param para tomar].
\end{abstract}

Como o osso que aciona o provérbio da mulher divorciada e casada novamente, o epíteto funciona como o núcleo de uma narrativa. Ele é ao mesmo tempo o estopim e o desfecho da história de Ajíbóyè. Em vez de apenas repetir o oríkì, ele o cita, explicitamente o reconhecendo como um texto que

3 A distribuição da produção de significado textual entre dois gêneros distintos e separadamente institucionalizados é um fenômeno que pode oferecer uma maneira prestativa de olhar para algumas das relações entre texto escrito e performance mencionadas acima. Por exemplo, pode-se pensar na commedia dell'arte não somente como uma relação entre "texto" e "performance" (ainda que obviamente o seja), mas também como um caso em que a constituição do drama está distribuída entre dois gêneros textuais - um escrito e o outro oral, nenhum tendo prioridade. 
preexistia ao momento presente da enunciação ${ }^{4}$. Depois de citá-lo, ele reforça a consolidação do oríki enquanto texto ao trazê-lo para escrutínio exegético.

Essa relação entre enunciado e exegese é um traço constitutivo do cântico de louvor por toda África subsaariana. Grande parte do cântico de louvor africano é constituída de modo a ser obscura, opaca ou alusiva. As canções ajogan dos reis de Porto Novo eram "deliberadamente alusivas e até herméticas" (Rouget 1971: 32). Os anciãos Ila, na Zâmbia, considerarão um cântico "que seja imediatamente autoevidente e que não possua camadas de alusão como um ipso facto desinteressante" (Rennie 1984: 530). Os recitadores de louvores apae da realeza e da chefia têm um vocabulário especial para "ocultar as mensagens" (Arhin 1986: 167); e de acordo com um dos informantes de Anyidoho, "a composição de cada apae era motivada por um evento histórico em particular. Portanto, além de delegar os textos à memória, um bom performer deveria também compreender os incidentes que os motivaram" (Anyidoho 1993: 119). A explicação do apae é, dessa maneira, encontrada na narrativa de sua origem, e os dois centros de informação - os louvores e as narrativas - são aprendidas e transmitidas paralelamente. Onde a tradição explicativa paralela é inacessível ou está perdida, os textos de louvor permanecem opacos: por exemplo, no reino Kuba, onde os cânticos em louvor aos monarcas - ensinados, palavra por palavra, às esposas da realeza por uma oficial mulher - frequentemente “consistem em alusões”, cuja "explicação ... não é uma parte do ensinamento em si”, de modo que “é difícil usá-los” para reconstruções históricas (Vansina 1978: p. 23).

Mbiímbi, a poesia dinástica dos conquistadores Lunda, falantes de Yaka no Sudoeste da República Democrática do Congo, "insinua os fatos em vez de os descrever ou de os contar e de os explicar à maneira de uma recitação história" (N’Soko SwaKabamba 1997). Em vez de se referir aos ancestrais heroicos por seus nomes o compositor-performer do mbiímbi pode evocá-los por meio de "nomes de poder" ou artifícios emblemáticos. Formas substantivadas, como em todo cântico de louvor, são formas de evitação, ao mesmo tempo que são formas de elaboração honorífica: elas conferem pseudônimos ao personagem. Consideremos os versos (N’Soko Swa-Kabamba 1997: 152):

Oh ele-que-boia-ao-longo-do-rio Broto que boiou na companhia das plantas aquáticas Oh, camaleão, o que viste em mim, Nteeba?

4 Para uma exploração mais completa da citação na constituição dos gêneros orais Yorùbá, ver Barber (1999). 
Esse cântico de louvor é sobre um rei, (“Se tens uma batalha legal com ele, tu [ficas] Muloombo, o qual nos contam ter reinado de 1902 a 1913. Ele foi deportado pelas autoridades belgas após decapitar dois de seus chefes de domínio colonial indireto. A forma substantivada "ele-queboia-ao-longo-do-rio" é ampliada e elaborada no verso seguinte, "Broto que boiou na companhia das plantas aquáticas": são alusões ao fato de que Muloombo foi exilado por via fluvial. O terceiro verso se apoia no conhecimento geral de que Muloombo era chamado de "camaleão" por causa de seu andar elegante e majestoso. Tal informação, no entanto, não está contida no texto; como diz N'Soko Swa-Kabamba, não se sabia ao que se referia sem o conhecimento de outra tradição, o nsámu mya tsyá khúlu ou "contos de outros tempos".

Uma expansão mais limitada pode também se dar dentro de um texto de cântico de louvor. Um modo muito comum de constituição textual consiste em apresentar um epíteto compacto, obscuro e substantivado e então, no texto subsequente, proceder a fim de estendê-lo e contextualizá-lo. Assim, no apae Asante, "quase todo verso começa com algo substantivado que é então explanado ou elaborado na forma de uma cláusula adjetiva sucessiva” (Anyidoho1933: 372). Por exemplo, Okoro-man-so-fone ("Aquele quevai-à-cidade-e-faz-todos-ficarem-emaciados") é elaborado com $A$ wo ne no twe manso wofon emaciado"). O segundo verso explana o contexto - o litígio - no qual é vivido o impacto devastador do personagem nas outras pessoas; sem essa elaboração, o epíteto de louvor seria ao mesmo tempo parco e enigmático. De maneira similar, no izibongo Xhosa, um modo comum de constituição textual é apresentar uma expressão substantivada compacta e de difícil compreensão e, em seguida, acrescentar um breve comentário: "Cabeça-(com)panos: alguns falam deles, outros de fato os carregam" ou "Pernas-inchadas: um defeito que está separado de outros defeitos” (Kuse 1979: 212, -210). No que Kuse chama de elogios complexos, a elaboração do epíteto substantivado pode tomar a forma de uma narrativa estendida, mais vagamente associada. Essas extensões internas apresentam e consolidam o texto sem constituir completamente seu significado. Em ambos os casos, Asante e Xhosa (e em muitos outros casos paralelos de outros lugares da África) parece evidente que há diversos tipos de expansão, elaboração e exegese construídos em camadas ao redor do epíteto substantivado central - alguns dentro do texto e alguns conduzidos fora em uma tradição narrativa paralela. A obscuridade - a apresentação de uma expressão lacônica, incompleta e alusiva - está, portanto, no centro de um modo complexo de constituição textual. 
A obscuridade nos cânticos de louvor poderia ser empregada por razões políticas. Poderia ser usada para codificar críticas discretas ao poder real e dinástico (veja Vail \& White 1991). Em contrapartida, poderia ser usada pelo grupo governante para ostentar a existência de segredos que eram entendidos como a base de seu poder, enquanto que o conteúdo é resguardado (Arhin 1986). Sugiro, contudo, que subjacente a isso está a questão mais fundamental do próprio modo pelo qual o texto é constituído para transcender tempo e espaço. A obscuridade provoca o ouvinte a atos de exegese que consolidam o enunciado enquanto um objeto de atenção.

Tal como um comentário externo, um comentário interno pode envolver um modo de citação. A substantivação pode, por assim dizer, referir-se a um trecho de discurso, estimá-lo pela relevância do tema e anunciar a adequação de sua atribuição a essa ou aquela pessoa. Assim, um louvador Yorùbá pode dizer (adaptado de Barber, 1991, p. 69):

'Ó gbó sésé Ifá ó yalé Ó gbéhìnkùlé moye odù tó hù "Àìgbớfá là á ń wòkè, Ifá kan ò sí n párá”"

Ló tó Babaa Fárónkẹ șe.

'Ele ouve o tinido da corrente divinatória, ele para a fim de entrar Ainda fora no terreiro ele já sabe qual figura emergiu

"Sem saber o Ifá, olhamos para cima, mas não há Ifá nas telhas"

É disso que o Pai de Fárónké é digno de ser chamado.
À primeira vista, os dois versos que abrem esse excerto soam como declarações proposicionais sobre uma pessoa; o terceiro verso é um provérbio, usado com a característica inversão Yorùbá para sugerir que o sujeito, ao contrário das pessoas referidas no provérbio, é profundamente versado em Ifá. Contudo, uma vez enunciados esses três versos, o performer então declara que é disso que o sujeito é digno de ser chamado - referindo-se em retrospecto à formulação inteira e oferecendo-a ao sujeito como uma atribuição que evoca suas qualidades. Portanto, as declarações não funcionam apenas enquanto epítetos ou equivalentessubstantivos, mas também são produzidos enquanto textos citados - textos que se reconhece preexistir ao presente momento de enunciação e que são apresentados, estimados e atribuídos ao sujeito. Essas formulações são, de fato, parte do repertório da cantadora de oríkì e podem ser aplicadas a qualquer um cujas habilidades de adivinho o torne merecedor; no próprio ato de atribuição, a cantadora realça esse fato, chamando atenção à preexistência da formulação, ao caráter de texto jáconstituído.

O poder do conceito de citação é que ele captura simultaneamente o processo de descolamento [detachment] e o processo de recontextualização. Uma citação só é uma citação quando é inserida em um novo contexto. Assim, no próprio ato de 
reconhecer um trecho como tendo uma existência independente, o citador está o reinserindo [ $r e-$ embedding]. Isso, eu sugiro, ajuda-nos a entender como "texto" (o trecho de discurso descolável e decontextualizado) e "performance" (o ato de juntar e mobilizar elementos discursivos) são os dois lados de uma moeda, inseparáveis e mutuamente constituintes.

Os enunciados densos, compactados e “objetificados" que venho discutindo podem ser mobilizadas em performances de fluidez, dinamismo e dialogicidade extraordinários. Uma performance de oríkì - e, embora talvez em menor escala, de vários outros gêneros de cânticos de louvor na África - é a articulação de fragmentos autônomos que poderiam a princípio ser performados em qualquer ordem, seleção e combinação. A incompletude compacta e a referencialidade das formulações as fazem se mobilizar em relação com as outras, pois para além do interior de sua própria narrativa cada uma aponta para expansão e exegese. Há no oríkì uma ênfase particular na profusão, porque nessa cultura de competição entre "grandes homens" [big men] que se autoengrandecem, quanto mais oríki forem acumulados sobre a figura do destinatário, mais se aumentará sua aura em relação a seus rivais. Isso significa que os performers não se restringem a um corpus autorizado para cada sujeito, mas que na busca por material para adicionarem ao fluxo oral, apoderam-se dos oríkì de outros sujeitos e, com efeito, de outros gêneros verbais, como provérbios, charadas e versos Ifá. Há uma intertextualidade generalizada nas quais elementos incorporados são parcialmente, mas não completamente, subordinados ao projeto do gênero incorporante, lançando uma névoa de "citabilidade" ao longo de todo o campo da oratura Yorùbá (Barber, 1999).

A coerência da performance de oríkì deriva da presença - real ou virtual - do personagem ao qual ela é dirigida, em quem convergem todas as atribuições, e do entusiasmo com o qual um performer habilidoso proferirá ligações tênues e temporárias entre as atribuições, baseando-se em similaridades de som ou sentido. Com um inabalável contato visual, o performer envolve o destinatário em uma relação diádica e intensa. Ela (ou ele) é intensamente responsiva à presença do destinatário - frequentemente o exortando, abençoando ou agradecendo, ou às vezes mudando para um novo sujeito quando uma personalidade mais importante entra no espaço da performance. Mesmo ao longo de seu intenso discurso ao sujeito de sua escolha, ela está reunindo um fluxo heterogêneo e misto de materiais que incorpora citações de numerosas fontes, citações essas que muitas vezes estão comprimidas, incompletas e obscuras. O resultado é que os oríkì são 
constituídos enquanto algo que flutua acima do real contexto de enunciação, escapando da situação dialógica concreta na qual ela é proferida, transcendendo o tempo e se apresentando como um objeto que requer exegese. Não obstante, é essa qualidade fugidia, fragmentada e migratória do oríkì que também o torna tão intensamente uma performance no aqui e agora - emergente, variável, constituído pela contingência, e forjado momento a momento à medida que o performer capta materiais com os quais responde à presença do destinatário.

O propósito deste artigo, portanto, foi demonstrar não apenas que as performances orais podem ser frutiferamente vistas como performances de "textos", mas também que, ao menos no caso do cântico de louvor africano, é a entextualização efetuada através da consolidação do discurso como objeto de exegese e como citação - que possibilita uma realização intensamente fluida e dinâmica do texto em performance. Logo, entextualização não é o oposto da performance emergente, é na verdade, o seu alter ego; as duas caminham de mãos dadas e são condição de possibilidade uma da outra. Isso porque, para que o texto obtenha significado, ele deve ser tratado como objeto de atenção - pela exegese e ao ser citado em novos contextos de enunciação -; ao passo que uma performance que fosse verdadeiramente efêmera seria uma performance de nada. 


\section{REFERÊNCIAS}

Anyidoho, L. A.1993. Gender and language use: the case of two akan verbal art forms. Tese de Doutorado, Universidade do Texas, Austin, EUA.

Arhin, K. 1986. The Asante Praise Poems: the ideology of patrimonialism. Paideuma, 32:163-97.

Barber, K. 1991. I Could Speak until Tomorrow: Orikì, Women and the Past in a Yoruba Town. Edimburgo: Edinburgh University Press for the International African Institute.

Barber, K. 1999. Quotation in the Constitution of Yorùbá Oral Texts. Research in African Literatures, 30.3:17-41.

Barber, K. 2005. Oral Tradition 20 (2): 264-277.

Barthes, R. 1974. S/Z. New York: Hill and Wang.

Collingwood, R. G. 1938. The Principles of Art. Oxford: Oxford University Press.

Duchartre, P. L. 1966 [1929]. The Italian Comedy. New York: Dover.

Hanks, W. F. 1989. Text and Textuality. Annual Review of Anthropology, 18:95-127.

Kuse, Wandile F. 1979. Izibongo zeenkosi (The Praises of Kings): Aspects of Xhosa Heroic Poetry. Research in African Literatures, 10.2:208-38.

Lea, K. M. 1962. Italian Popular Comedy: A Study in the Commedia Dell'arte, 1560-1620, with Special Reference to the English Stage. New York: Russell and Russell.

N’Soko Swa-Kibamba, J. 1997. The Mbiímbi, a Panegyric Dynastic Poem of the Yaka, and its Principal Characteristics. Research in African Literatures, 28:141-58. 
Penfield, J. P. 1983. Communicating with Quotes: The Igbo Case. Westport, CT, Londres: Greenwood Press.

Rennie, J. K. 1984. Cattle, Conflict and Court Cases: The Praise Poetry of Ila Leadership. Research in African Literatures, 15:530-67.

Rouget, G. 1971. Court Songs and Traditional History in the Ancient Kingdoms of Porto-Novo and Abomey, in Essays on Music and History in Africa. Editado por K. P. Wachsmann, pp. 27-64. Evanston: Northwestern University Press.

Silverstein, M; Urban, G. Editores. 1996. Natural Histories of Discourse. Chicago: University of Chicago Press.

Stewart, G. 1996. Dear Reader: The Conscripted Audience in Nineteenth-Century British Fiction. Baltimore: Johns Hopkins University Press.

Urban, Greg. 1991. A Discourse-Centered Approach to Culture. Austin: University of Texas Press.

Urban, Greg. 1996. Entextualization, Replication and Power in Silverstein, M., G. Urban, Editores. 1996. Natural Histories of Discourse. Chicago: University of Chicago Press.

Vail, V., White, L. 1991. Power and the praise poem: Southern African voices in history. Charlottesville: University Press of Virginia.

Vansina, J. 1978. The children of woot: a history of the Kuba Peoples. Madison: University of Wisconsin Press.

Yankah, K. 1989. The Proverb in the Context of Akan Rhetoric. New York: Peter Lang.

Yankah, K. 1994. Visual IIcons and the Akan concept of proverb authorship. Passages: A chronicle of the humanities, 7:13. 
